\title{
AVALIAÇÃO ECONÔMICA DE TÉCNICAS DE RECUPERAÇÃO DE PASTAGENS`1
}

\author{
LIDIA PACHECO YOKOYAMA ${ }^{2}$, ANTÔNIO VIANA FILHO ${ }^{3}$, LUIZ CARLOS BALBINO 4 , \\ ITAMAR PEREIRA DE OLIVEIRA ${ }^{5}$ e ALEXANDRE DE OLIVEIRA BARCELLOS ${ }^{6}$
}

\begin{abstract}
RESUMO - O objetivo deste trabalho foi comparar a economicidade de algumas técnicas de recuperação de pastagens, ao longo de um período, avaliando o desempenho animal sob pastejo rotacionado. As atividades foram desenvolvidas em Brasilândia, MS, em seis módulos de cinco hectares cada. Os módulos T1 (milho + Brachiaria brizantha), T2 (arroz + B. brizantha) e T3 (arroz + B. brizantha + Calopogonium mucunoides) foram renovados de acordo com a técnica preconizada pelo Sistema Barreirão. O módulo T4 foi formado de acordo com método convencional da região com $B$. brizantha. Os módulos T5 e T6 foram selecionados nas proximidades dos demais módulos como testemunhas, predominando a $B$. humidicola no módulo T5 e $B$. humidicola e $B$. decumbens no módulo T6. A avaliação econômica foi baseada na produção de grãos, ganho de peso e na lotação animal. Os resultados encontrados nos sistemas analisados, nos módulos T1, T2, T3 e T4 demonstram que a exploração da pecuária bovina de corte, no pasto recuperado, é uma atividade economicamente lucrativa, e que os módulos T1, T2 e T3 apresentam vantagem comparativa, devido à produção de grãos que cobre parte dos custos de formação da pastagem.
\end{abstract}

Termos para indexação: Sistema Barreirão, cultivos associados, milho, arroz, leguminosa, Brachiaria brizantha, lotação animal, ganho de peso animal.

\section{ECONOMIC EVALUATION OF DIFFERENT TECHNOLOGIES FOR PASTURE RECUPERATION}

\begin{abstract}
The aim of this study was to compare the economic viability of some technologies for recovery of degraded pastures, for a period of time, evaluating animal development under rotational grazing. The activities were conducted in Brasilândia, MS, Brazil, studying six modules of 5 ha each. Modules T1 (corn + Brachiaria brizantha), T2 (rice $+B$. brizantha), and $\mathrm{T} 3$ (rice $+B$. brizantha + Calopogonium mucunoides) had been renewed following the procedures recomended by the "Barreirão System". Module T4 had been formed according to traditional regional procedures, with $B$. brizantha. Modules T5 and T6 were selected in the vicinity of the others, to serve as controls; $B$. humidicola was predominant in module T5, whereas module T6 was predominantly formed by $B$. humidicola and B. decumbens. Economic evaluation was based on cereal production, live weight gain and stocking rate. It was observed that in modules T1, T2, T3, and T4, exploration of beef cattle grazing on recovered pastures is a profitable activity. Pasture renewal according to agricultural modules T1, T2, and T3 have advantages over the traditional models due to the cereal production which defrays the cost to recover the pastures.

Index terms: "Barreirão System", associated crops, corn, rice, legumes, Brachiaria brizantha, stocking rate, animal live weight gain.
\end{abstract}

\footnotetext{
${ }^{1}$ Aceito para publicação em 31 de agosto de 1998.

${ }^{2}$ Econ. Agrária, M.Sc., Embrapa-Centro Nacional de Pesquisa de Arroz e Feijão (CNPAF), Caixa Postal 179, CEP 74001-970 Goiânia, GO. E-mail: lidia@cnpaf.embrapa.br ${ }^{3}$ Méd. Vet., M.Sc., Universidade Católica de Goiás (UCG), Av. Universitária, 1440, CEP 74605-010 Goiânia, GO.
}

\footnotetext{
${ }^{4}$ Eng. Agr., Embrapa-CNPAF.

${ }^{5}$ Eng. Agr., Dr., Embrapa-CNPAF.

${ }^{6}$ Zoot., M.Sc., Embrapa-Centro de Pesquisa Agropecuária dos Cerrados (CPAC), Caixa Postal 08223, CEP 73301-970 Planaltina, DF.
} 


\section{INTRODUÇÃO}

Os maiores problemas da exploração da pecuária estão na deficiência e baixa qualidade das pastagens no período seco do ano, o que prejudica o desempenho produtivo do rebanho. Nesse período, as pastagens, além da escassez, apresentam baixo valor nutritivo, baixo coeficiente de digestibilidade e pouca palatabilidade para o gado, resultando em consideráveis prejuízos para os criadores, pela baixa eficiência produtiva e reprodutiva do rebanho.

Nos últimos anos, muitas informações foram geradas pela pesquisa, dando origem a várias tecnologias de recuperação de pastagem, destacando-se as seguintes: recuperação direta, utilizandose corretivos de acidez, adubação e manejo do solo (Zimmer et al., 1994); recuperação, utilizando-se rotação com cultivos anuais de média (Seguy et al., 1994) e curta duração (Zimmer et al., 1994); e recuperação, consorciando-se culturas anuais com forrageiras, principalmente dos gêneros Brachiaria e Andropogon.

Cada uma dessas tecnologias aplica-se a casos específicos, no que se refere às condições sócio-econômicas e de aptidão do produtor. A recuperação direta, tecnificada, exige elevado profissionalismo dos pecuaristas para inversão do capital aplicado, em curto período de tempo. A recuperação baseada na rotação com culturas anuais exige profissionalismo do produtor, tanto na pecuária como na agricultura, além de demandar máquinas, implementos e instalações. A recuperação pelo consórcio traz mudanças substanciais nas práticas de manejo do solo e da cultura, porém exige, em média, menos investimentos que o método de rotação (Oliveira et al., 1996).

O objetivo deste trabalho foi comparar a economicidade de algumas técnicas de recuperação de pastagens, ao longo de um período, através do desempenho animal sob pastejo rotacionado.

\section{MATERIAL E MÉTODOS}

As atividades de recuperação de pastagens foram introduzidas na Fazenda Modelo, município de Brasilândia, MS, em solo de classe Latossolo VermelhoAmarelo distrófico, muito arenoso.
O desempenho animal foi avaliado em seis módulos de $5 \mathrm{ha} /$ módulo, perfazendo uma área total de 30 ha.

Os módulos formados foram os seguintes: T1 - Área renovada pelo Sistema Barreirão (milho + Brachiaria brizantha); T2 - Área renovada pelo Sistema Barreirão (arroz + Brachiaria brizantha); T3 - Área renovada pelo Sistema Barreirão (arroz + Calopogonium mucunoides + Brachiaria brizantha); T4 - Área renovada pelo método convencional com Brachiaria brizantha; T5 - Área formada com Brachiaria humidicola (pastagens em processo de degradação); T6 - Área formada com Brachiaria humidicola e $B$. decumbens (pastagens em processo de degradação)

Os módulos T1, T2 e T3 foram renovados de acordo com a técnica preconizada pelo Sistema Barreirão, da Embrapa-Centro Nacional de Pesquisa de Arroz e Feijão (CNPAF) (Kluthcouski et al., 1991). O módulo T4 foi formado de acordo com método convencional (tradicional) da região.

Nos módulos formados pelo Sistema Barreirão (T1, T2 e T3) e pelo método convencional (T4) os plantios foram efetuados entre 17 e 20 de novembro de 1994, e os demais (T5 e T6) foram vedados na mesma época.

No módulo T1, fez-se a aplicação de 3 t/ha de calcário, gradagem no período da seca e aração com arado de aivecas. Após a gradagem niveladora, foi semeado o milho utilizando-se uma adubação, na linha de plantio, de $454 \mathrm{~kg} / \mathrm{ha}$ da fórmula 4-30-16, $39 \mathrm{~kg} / \mathrm{ha}$ de micronutrientes (FTE BR12) e $32 \mathrm{~kg} / \mathrm{ha}$ de sulfato de zinco. Misturados aos fertilizantes, foram colocados $6,5 \mathrm{~kg} / \mathrm{ha}$ de sementes de Brachiaria brizantha $(\mathrm{VC}=40 \%)$. Em cobertura, foram aplicados $250 \mathrm{~kg} / \mathrm{ha}$ de sulfato de amônio, 40 dias após o plantio.

$\mathrm{O}$ módulo $\mathrm{T} 2$ recebeu a mesma seqüência de preparo de solo do módulo T1. A correção e fertilização do solo foram feitas com duas toneladas/ha de calcário, $300 \mathrm{~kg} / \mathrm{ha}$ da fórmula 4-30-16, $30 \mathrm{~kg} / \mathrm{ha}$ de micronutrientes (FTE BR12), $20 \mathrm{~kg} / \mathrm{ha}$ de sulfato de zinco e, misturados aos fertilizantes, $5 \mathrm{~kg} / \mathrm{ha}$ de sementes de Brachiaria brizantha $(\mathrm{VC}=40 \%)$. Em cobertura, foram aplicados 100 e $50 \mathrm{~kg} / \mathrm{ha}$ de sulfato de amônio e cloreto de potássio, respectivamente.

O módulo T3 foi conduzido de modo idêntico ao módulo T2, sendo acrescentados mais $3 \mathrm{~kg} / \mathrm{ha}$ de semente da leguminosa Calopogonium mucunoides, misturados aos fertilizantes juntamente com as sementes de Brachiaria brizantha.

No módulo T4, o preparo do solo e a correção tiveram as seguintes seqüências: aplicação de 1,4 t/ha de calcário, gradagem com grade aradora na seca, aplicação de $165 \mathrm{~kg} /$ ha de superfosfato simples no início da estação de 
chuvas, gradagem com grade aradora, distribuição a lanço de $12,5 \mathrm{~kg} / \mathrm{ha}(\mathrm{VC}=40 \%)$ de sementes de Brachiaria brizantha e passagem do rolo compactador.

Foi feito o acompanhamento de custo de produção dos quatro módulos, usando os preços reais praticados na fazenda, transformado em dólar da época da operação. Consideraram todos os itens do custo de produção de uma lavoura (máquinas, mão-de-obra e insumos), desde o preparo do solo à colheita, secagem e armazenagem.

Os módulos T5 e T6 foram selecionados nas proximidades dos demais módulos como testemunhas, predominando a $B$. humidicola no módulo T5 e $B$. humidicola e $B$. decumbens no módulo T6. Nessas áreas, as pastagens haviam sido implantadas havia cerca de 20 anos.

De acordo com o Sistema Barreirão, as pastagens estão em condições de serem utilizadas 60 dias após a colheita do arroz. No consórcio com o milho, a utilização poderá ser imediatamente após a colheita do mesmo. Entretanto, nos módulos 2 e 3 (consórcio de arroz + braquiária e arroz + calopogônio + braquiária), com o acamamento total da cultura, a colheita do arroz foi realizada com corte baixo, danificando a forrageira (braquiária ou calopogônio). Como conseqüência, houve a necessidade de prolongar o período de vedação além do preconizado. A utilização das pastagens somente ocorreu em 17/11/95, data da colocação de animais em todos os módulos. Cada módulo com uma área de cinco hectares foi dividido em piquetes de um hectare.

A idade média dos animais colocados foi de nove meses. Esses animais foram colocados em cada um dos módulos (piquetes), de acordo com a oferta de forragem, com base na matéria verde seca (MVS). Amostragens periódicas da oferta de forragem por piquete foram tomadas antes do ingresso dos animais (oito amostras de $0,5 \mathrm{~m}^{2}$ por piquete). Nas amostras, efetuou-se a separação da parte verde e material morto.

De acordo com o planejamento inicial, o sistema de pastejo adotado foi o rotacionado com sete dias de ocupação/piquete e 28 dias de descanso até 10/4/96, quando foi então alterado para nove dias de ocupação/piquete e 36 de descanso.

Os animais foram pesados nas mesmas datas de amostragens das gramíneas, com o objetivo de se fazer um ajuste constante da lotação, com base na oferta da forragem. Inicialmente, adotou-se uma oferta de $6 \mathrm{~kg}$ de MVS/100 kg de peso vivo/dia (PP - pressão de pastejo de 6\%) para todos os módulos. A partir de 10/4/96, passouse a pressão de pastejo (PP) para $7 \%$. Na entrada dos animais nas áreas em 17/11/95, foram escolhidos seis animais, chamados "testers", de dois grupos sangüíneos (três Nelores e três cruzados Nelore x Blond), que são fixos em cada módulo, pesados individualmente, e que servem de parâmetros estatísticos das avaliações de ganho de peso.

Para o ajuste da pressão de pastejo empregaram-se animais "volantes" que foram adicionados ou retirados dos módulos conforme a oferta de forragem por ocasião das pesagens. Esses animais foram pesados em conjunto, e seus ganhos de peso fazem parte dos cálculos de lotação e produção por hectare, com base no ganho dos animais "testers". Foram também selecionados dez animais, dos mesmos grupos sangüíneos, que após marcação individualizada seguiram no manejo tradicional da fazenda (testemunha absoluta).

Para o cálculo da lotação do módulo/dia (LMD), foi considerada a média ponderada, segundo a fórmula:

$$
\mathrm{LMD}=\frac{\text { Somatório } \mathrm{n}^{\mathrm{o}} \text { de animais } \mathrm{x} \mathrm{n}^{\mathrm{o}} \text { dias no módulo }}{\text { Somatório } \mathrm{n}^{\mathrm{o}} \text { dias no módulo }}
$$

ou

$$
\mathrm{LMD}=\sum_{\mathrm{i}=1}^{10}(\mathrm{NA} * \mathrm{NDM}) / \sum_{\mathrm{i}=1}^{10} \mathrm{NDM}
$$

onde:

$\mathrm{NA}=\mathrm{n}^{\mathrm{o}}$ de animais;

$\mathrm{NDM}=\mathrm{n}^{\mathrm{o}}$ de dias no módulo.

Para o cálculo da lotação hectare/dia (LHD), dividiuse pelo número de hectares de cada módulo.

$\mathrm{LHD}=\mathrm{LMD} / \mathrm{ha}$

onde:

ha $=\mathrm{n}^{\mathrm{o}}$ de hectares de cada módulo.

Para a transformação do ganho de peso de $\mathrm{kg} / \mathrm{ha} / \mathrm{ano}$ em arrobas/ha/ano, por se tratar de animais não-acabados, usou-se o percentual de $43 \%$, baseado em Arruda et al. (1992).

Pelo fato de se estar analisando a pecuária bovina de corte a pasto, na fase de engorda, a área total trabalhada de 5 ha/módulo se torna economicamente inviável, pois maximiza o efeito da deseconomia de escala (altos custos fixos) (Costa \& Martins, 1991, citados por Arruda et al., 1992; Arruda \& Correa, 1992).

Considerando esse fator, os resultados encontrados foram extrapolados para módulos de 100 ha (cinco piquetes de $20 \mathrm{ha}$ ). Vale ressaltar que ao aumentar ainda mais o tamanho dos módulos, haverá maior diluição dos custos fixos, sem modificação da tendência dos resultados encontrados nos diversos sistemas.

$\mathrm{Na}$ montagem do custo total e anual dos investimentos, consideraram-se como investimentos os itens pasta- 
gem (depreciada em cinco anos), calagem (três anos), cercas (15 anos) e bebedouros (30 anos). Não foi considerada a compra dos animais, mas também não foi considerada a receita do descarte dos mesmos. Para o cálculo dos juros do capital empregado nos investimentos, usou-se uma taxa de $6 \%$ a.a.

Na elaboração dos custos operacionais, no item administração e serviços, considerou-se a mesma necessidade de mão-de-obra para os seis módulos, enquanto o item insumos (medicamentos) variou de acordo com a lotação animal (número de cabeças) em cada módulo.

O término do ciclo de avaliações foi previsto para maio/97, época de troca de animais e reinício de um novo ciclo.

Neste trabalho, a avaliação dos sistemas abrange o período de um ano após a colocação dos animais $(17 / 11 / 95$ a $12 / 11 / 96)$.

A avaliação econômica foi baseada em análise de investimentos, calculando-se a relação benefício/custo e a taxa interna de retorno (Hoffmann et al., 1981).

\section{RESULTADOS E DISCUSSÃO}

Os módulos T1, T2 e T3 foram implementados nos moldes de agricultura consorciada com pastagem, preconizando a reforma no sexto ano, novamente com a cultura. Os resultados econômicos da produção de grãos encontram-se na Tabela 1. Observa-se que a produção de grãos nos módulos T1, T2 e T3 amortizou o custo de produção da renovação da pastagem em $49 \%, 82 \%$ e $95 \%$, respectivamente.
É importante observar que no caso do módulo $\mathrm{T} 1$, o rendimento do milho $(2.040 \mathrm{~kg} / \mathrm{ha})$ foi muito aquém do potencial médio conseguido no Sistema Barreirão, que é de $3.600 \mathrm{~kg} / \mathrm{ha}$ (Yokoyama et al., 1995). Neste trabalho, simulou-se este rendimento, e a relação benefício/custo tornou-se ainda mais atrativa $(0,87)$, ou seja, $87 \%$ dos custos da produção do milho e da pastagem teriam sido pagos com a produção do milho.

Vale ressaltar que no módulo T3 o acamamento do arroz foi em menor intensidade e a produtividade de grãos apresentada foi de 32 sacos de $60 \mathrm{~kg}$, enquanto no módulo $\mathrm{T} 2$ a produtividade conseguida foi de 25 sacos de $60 \mathrm{~kg}$. No módulo T3, a relação benefício/custo foi de 0,95 , significando que $95 \%$ dos custos de produção do arroz e da pastagem foram pagos com a produção do arroz. Portanto, o hectare de pastagem formada custou apenas $\mathrm{R} \$ 18,12$ (Tabela 1).

A Tabela 2 apresenta a composição do custo total e anual dos investimentos em benfeitorias e instalações. O capital imobilizado no processo produtivo foi transformado em valores anuais por meio do cálculo dos juros e depreciações, expressos em dólares.

$\mathrm{Na}$ Tabela 3, onde é apresentado o cálculo dos custos operacionais, verifica-se que cerca de $92 \%$ a $94 \%$, do custo total anual, são representados pelas despesas de pessoal, incluindo a remuneração do proprietário, pelo seu papel de administrador-geral,

TABELA 1. Custo de produção (US\$/ha) da formação de pastagem em consórcio com culturas anuais (T1, T2 e T3) e formação de pastagem convencional (T4).

\begin{tabular}{lrrrc}
\hline Itens & Módulo T1 & Módulo T2 & Módulo T3 & Módulo T4 \\
\hline Preparo do solo & 31,06 & 31,06 & 31,06 & 20,69 \\
Plantio & 259,16 & 202,24 & 237,33 & 70,43 \\
Tratos culturais & 136,71 & 62,64 & 62,64 & - \\
Colheita & 44,33 & 48,25 & 50,29 & - \\
Administração & 15,43 & 11,20 & 11,20 & 2,81 \\
Custo total da formação da pastagem & 486,69 & 355,39 & 392,52 & 93,93 \\
Receita com a cultura & 238,68 & 292,50 & 374,40 & - \\
Custo líquido da formação da pastagem & 248,01 & 62,89 & 18,12 & - \\
Relação benefício/custo & 0,49 & 0,82 & 0,95 & - \\
(\% de amortização no custo de formação) & & & & \\
\hline
\end{tabular}


de oito salários mínimos, o equivalente ao salário mínimo profissional do agrônomo. Está computado também no gerenciamento técnico-administrativo, ao custo de um salário mínimo, a assistência veterinária, imputada como um dia de trabalho por ano.
O custo total anual (custos operacionais + investimentos) encontra-se na Tabela 4 . A variação nos custos operacionais foi em função dos insumos (medicamentos), que foi calculado de acordo com a lotação animal de cada módulo.

TABELA 2. Composição do custo anual dos investimentos em benfeitorias e instalações (US\$).

\begin{tabular}{|c|c|c|c|c|c|c|c|c|c|}
\hline \multirow[t]{2}{*}{ Componente } & \multirow[t]{2}{*}{ Unid. } & \multirow[t]{2}{*}{ Quant. } & \multirow{2}{*}{$\begin{array}{c}\text { Valor } \\
\text { unitário }\end{array}$} & \multirow{2}{*}{$\begin{array}{c}\text { Total } \\
\text { investido }\end{array}$} & \multicolumn{2}{|c|}{ Juros } & \multicolumn{2}{|c|}{ Depreciação } & \multirow{2}{*}{$\begin{array}{c}\text { Investi- } \\
\text { mento anua }\end{array}$} \\
\hline & & & & & Taxa anual & Valor & Anos & Valor & \\
\hline \multicolumn{10}{|c|}{ Módulo T1 } \\
\hline Pastagem & ha & 100 & 248,01 & $24.801,00$ & 6 & $1.488,06$ & 5 & $4.960,20$ & $6.448,26$ \\
\hline Calagem & ha & 100 & 42,96 & $4.296,00$ & 6 & 257,76 & 3 & $1.432,00$ & $1.689,76$ \\
\hline Cercas & $\mathrm{m}$ & 8.000 & 1,58 & $12.640,00$ & 6 & 758,40 & 15 & 842,67 & $1.601,07$ \\
\hline Bebedouros & $\mathrm{n}^{\mathrm{o}}$ & 2 & 100,00 & 200,00 & 6 & 12,00 & 30 & 6,67 & 18,67 \\
\hline Total & & & & $41.937,00$ & & $2.516,22$ & & $7.241,54$ & $9.757,76$ \\
\hline \multicolumn{10}{|c|}{ Módulo T2 } \\
\hline Pastagem & ha & 100 & 62,89 & $6.289,00$ & 6 & 377,34 & 5 & $1.257,80$ & $1.635,14$ \\
\hline Calagem & ha & 100 & 29,31 & $2.931,00$ & 6 & 175,86 & 3 & 977,00 & $1.152,86$ \\
\hline Cercas & $\mathrm{m}$ & 8.000 & 1,58 & $12.640,00$ & 6 & 758,40 & 15 & 842,67 & $1.601,07$ \\
\hline Bebedouros & $\mathrm{n}^{\mathrm{o}}$ & 2 & 100,00 & 200,00 & 6 & 12,00 & 30 & 6,67 & 18,67 \\
\hline Total & & & & $22.060,00$ & & $1.323,60$ & & $3.084,14$ & $4.407,74$ \\
\hline \multicolumn{10}{|c|}{ Módulo T3 } \\
\hline Pastagem & ha & 100 & 18,12 & $1.812,00$ & 6 & 108,72 & 5 & 362,40 & 471,12 \\
\hline Calagem & ha & 100 & 29,31 & $2.931,00$ & 6 & 175,86 & 3 & 977,00 & $1.152,86$ \\
\hline Cercas & $\mathrm{m}$ & 8.000 & 1,58 & $12.640,00$ & 6 & 758,40 & 15 & 842,67 & $1.601,07$ \\
\hline Bebedouros & $\mathrm{n}^{\mathrm{o}}$ & 2 & 100,00 & 200,00 & 6 & 12,00 & 30 & 6,67 & 18,67 \\
\hline Total & & & & $17.583,00$ & & $1.054,98$ & & $2.188,74$ & $3.243,72$ \\
\hline \multicolumn{10}{|c|}{ Módulo T4 } \\
\hline Pastagem & ha & 100 & 110,26 & $11.026,00$ & 6 & 661,56 & 5 & $2.205,20$ & $2.866,76$ \\
\hline Calagem & ha & 100 & 16,33 & $1.633,00$ & 6 & 97,98 & 3 & 544,33 & 642,31 \\
\hline Cercas & $\mathrm{m}$ & 8.000 & 1,58 & $12.640,00$ & 6 & 758,40 & 15 & 842,67 & $1.601,07$ \\
\hline Bebedouros & $\mathrm{n}^{\mathrm{o}}$ & 2 & 100,00 & 200,00 & 6 & 12,00 & 30 & 6,67 & 18,67 \\
\hline Total & & & & $25.499,00$ & & $1.529,94$ & & $3.598,87$ & $5.128,81$ \\
\hline \multicolumn{10}{|c|}{ Módulo T5 } \\
\hline Cercas & $\mathrm{m}$ & 8.000 & 1,58 & $12.640,00$ & 6 & 758,40 & 15 & 842,67 & $1.601,07$ \\
\hline Bebedouros & $\mathrm{n}^{\mathrm{o}}$ & 2 & 100,00 & 200,00 & 6 & 12,00 & 30 & 6,67 & 18,67 \\
\hline Total & & & & $12.840,00$ & & 770,40 & & 849,34 & $1.619,74$ \\
\hline \multicolumn{10}{|c|}{ Módulo T6 } \\
\hline Cercas & $\mathrm{m}$ & 8.000 & 1,58 & $12.640,00$ & 6 & 758,40 & 15 & 842,67 & $1.601,07$ \\
\hline Bebedouros & $\mathrm{n}^{\mathrm{o}}$ & 2 & 100,00 & 200,00 & 6 & 12,00 & 30 & 6,67 & 18,67 \\
\hline Total & & & & $12.840,00$ & & 770,40 & & 849,34 & $1.619,74$ \\
\hline
\end{tabular}


TABELA 3. Composição do valor anual dos custos operacionais de uma área de 100 ha (US\$).

\begin{tabular}{|c|c|c|c|c|}
\hline Componente & Unidade $^{1}$ & $\begin{array}{c}\text { Quantidade } \\
\text { anual }\end{array}$ & $\begin{array}{c}\text { Valor } \\
\text { unitário }\end{array}$ & $\begin{array}{l}\text { Valor } \\
\text { total }\end{array}$ \\
\hline \multicolumn{5}{|l|}{ Administração e serviços } \\
\hline Gerência e assist. veterinária & SM & $(8 \times 13)+1$ & 112,00 & $11.760,00$ \\
\hline \multicolumn{5}{|l|}{ Mão-de-obra permanente } \\
\hline Capataz & SM & $2 \times 13$ & 112,00 & $2.912,00$ \\
\hline Peão & SM & $1,5 \times 13$ & 112,00 & $2.184,00$ \\
\hline Mão-de-obra eventual & HD & 10 & 12,00 & 120,00 \\
\hline Encargos sociais & $\%$ & 35 & & $5.941,60$ \\
\hline Subtotal anual dos custos operacionais & & & & $22.917,60$ \\
\hline \multicolumn{5}{|c|}{ Módulo T1 } \\
\hline Custos operacionais/módulo & & & & $22.917,60$ \\
\hline Medicamentos (vacinas, vermífugos, etc) & Dose & $487,60 \mathrm{cab} . \times 6$ & 0,17 & 497,35 \\
\hline Juros s./capital exploração & & $6 \%$ a.a. & & $1.404,90$ \\
\hline Total & & & & $24.819,85$ \\
\hline \multicolumn{5}{|c|}{ Módulo T2 } \\
\hline Custos operacionais/módulo & & & & $22.917,60$ \\
\hline Medicamentos (vacinas, vermífugos, etc) & Dose & $385,80 \mathrm{cab} . \times 6$ & 0,17 & 393,53 \\
\hline Juros s./capital exploração & & $6 \%$ a.a. & & $1.398,67$ \\
\hline Total & & & & $24.709,80$ \\
\hline \multicolumn{5}{|c|}{ Módulo T3 } \\
\hline Custos operacionais/módulo & & & & $22.917,60$ \\
\hline Medicamentos (vacinas, vermífugos, etc) & Dose & 449,20 cab. $\times 6$ & 0,17 & 458,18 \\
\hline Juros s./capital exploração & & $6 \%$ a.a. & & $1.402,55$ \\
\hline Total & & & & $24.778,33$ \\
\hline \multicolumn{5}{|c|}{ Módulo T4 } \\
\hline Custos operacionais/módulo & & & & $22.917,60$ \\
\hline Medicamentos (vacinas, vermífugos, etc) & Dose & $384,20 \mathrm{cab} . \times 6$ & 0,17 & 391,88 \\
\hline Juros s./capital exploração & & $6 \%$ a.a. & & $1.398,57$ \\
\hline Total & & & & $24.708,05$ \\
\hline \multicolumn{5}{|c|}{ Módulo T5 } \\
\hline Custos operacionais/módulo & & & & $22.917,60$ \\
\hline Medicamentos (vacinas, vermífugos, etc) & Dose & 209,40 cab. $\times 6$ & 0,17 & 213,59 \\
\hline Juros s./capital exploração & & $6 \%$ a.a. & & $1.387,87$ \\
\hline Total & & & & $24.519,06$ \\
\hline \multicolumn{5}{|c|}{ Módulo T6 } \\
\hline Custos operacionais/módulo & & & & $22.917,60$ \\
\hline Medicamentos (vacinas, vermífugos, etc) & Dose & $234,60 \mathrm{cab} . \times 6$ & 0,17 & 239,29 \\
\hline Juros s./capital exploração & & $6 \%$ a.a. & & $1.389,41$ \\
\hline Total & & & & $24.546,30$ \\
\hline
\end{tabular}

${ }^{1}$ SM: salário mínimo; HD: homens dias. 
O ganho de peso no primeiro ano foi analisado e consta na Tabela 5. Comparando-se o ganho de peso dos animais entre os módulos, observa-se que houve uma variação de 3\% a $86 \%$ em relação ao módulo T6, considerado como testemunha (100\%). Esta variação no ganho de peso dos animais foi devida à diferenciação na lotação animal entre os módulos. Nos módulos, a lotação animal foi de: $\mathrm{T} 1=4,88 ; \mathrm{T} 2=3,86 ; \mathrm{T} 3=4,49 ; \mathrm{T} 4=3,84 ;$ $\mathrm{T} 5=2,09$ e $\mathrm{T} 6=2,35 \mathrm{cab} . / \mathrm{ha}$. Verifica-se que no módulo T1 a lotação animal foi maior em 133\% em relação ao módulo $\mathrm{T} 5$. Os animais selecionados e submetidos ao manejo da fazenda tiveram menor ganho de peso em relação aos animais manejados nos módulos. O peso médio inicial dos animais foi de $176 \mathrm{~kg} / \mathrm{cab}$., e no final do período de avaliação, após um ano, o peso final dos animais foi de $257 \mathrm{~kg} / \mathrm{cab}$.

TABELA 4. Custo operacional, investimentos e total anual.

\begin{tabular}{cccc}
\hline Módulos & \multicolumn{2}{c}{ Custo total anual (US\$) } & Custo \\
\cline { 2 - 3 } & $\begin{array}{c}\text { Custos } \\
\text { operacionais }\end{array}$ & Investimentos & total (US\$) \\
\hline T1 & $24.819,85$ & $9.757,75$ & $34.577,60$ \\
T2 & $24.709,80$ & $4.407,73$ & $29.117,53$ \\
T3 & $24.778,33$ & $3.243,71$ & $28.022,04$ \\
T4 & $24.708,05$ & $5.128,81$ & $29.836,86$ \\
T5 & $24.519,06$ & $1.619,73$ & $26.138,79$ \\
T6 & $24.546,30$ & $1.619,73$ & $26.166,03$ \\
\hline
\end{tabular}

TABELA 5. Ganho de peso de carcaça $\mathrm{kg} / \mathrm{ha} / \mathrm{ano}$, $\mathrm{kg} / 100$ ha e arrobas/100 ha/ano.

\begin{tabular}{cccc}
\hline Módulos & $\mathrm{kg} / \mathrm{ha} / \mathrm{ano}$ & $\mathrm{kg} / 100 \mathrm{ha}$ & ${\text { Arroba} / 100 \mathrm{ha} / \mathrm{ano}^{1}}^{1}$ \\
\hline T1 & 699,45 & $69.945,00$ & $2.005,09(186)$ \\
T2 & 610,11 & $61.011,00$ & $1.748,98(162)$ \\
T3 & 673,60 & $67.360,00$ & $1.930,99(179)$ \\
T4 & 619,03 & $61.903,00$ & $1.774,55(165)$ \\
T5 & 387,09 & $38.709,00$ & $1.109,66(103)$ \\
T6 & 375,49 & $37.549,00$ & $1.076,40(100)$ \\
\hline
\end{tabular}

${ }^{1}$ Valores entre parênteses são porcentagens relativas (T6=100\%).
$\mathrm{O}$ custo do investimento total em US\$/arroba carcaça e o custo médio de produção em US\$/arroba carcaça, estão mostrados na Tabela 6 . O custo médio de produção de uma arroba de carcaça nos módulos T1, T2, T3 e T4 permite uma margem de renda líquida, pois a média histórica dos preços reais de mercado do boi gordo tem sido cerca de US\$ 20,00 (Arruda et al., 1992). Neste caso os cálculos foram desenvolvidos com base no preço da arroba (US\$ 18,00) do boi magro (não-acabado) e verificou-se que a taxa de retorno variou entre 1,04 a 1,24 , com lucro de $4 \%$ a $24 \%$ no investimento. Nos módulos T5 e T6 apenas 76\% e 74\%, respectivamente, dos custos foram pagos.

A extrapolação dos dados para 100 ha permitiu a elaboração da estimativa do fluxo de caixa para um período de cinco anos (Tabela 7), mostrando a receita líquida e ainda a relação benefício/custo, considerando igualmente os itens analisados (receitas e despesas). Foi estimado o fluxo para cinco anos, pois preconiza-se que no sexto ano implanta-se a cultura novamente.

No fluxo de caixa, para o cálculo das despesas e receitas referente ao primeiro ano, consideraram-se, para os módulos T1 e T4, seis meses de cultivo e seis meses de ganho de peso. Para os módulos T2 e T3, consideraram-se sete meses para o cultivo do arroz e cinco meses de ganho de peso. Para os anos seguintes, partiu-se do pressuposto de que o ganho de peso será o mesmo conseguido no primeiro ano.

Analisando a relação benefício/custo do fluxo de caixa, observa-se que o módulo T3 apresentou resultados maiores que um em todo o período analisado, pois o investimento feito com a reforma da pastagem foi quase integralmente remunerado com a produção do arroz.

$\mathrm{Na}$ análise de investimento (semestral), as taxas internas de retorno e as relações benefício/custo (taxa de desconto de $10 \%$ ) encontradas foram as seguintes: $\mathrm{T} 3=414,80 \%(1,25) ; \mathrm{T} 2=86,19 \%(1,08)$; $\mathrm{T} 4=60,61 \%(1,06) ; \mathrm{T} 1=19,11 \%(1,02) ;$ e os módulos T5 e T6 apresentaram relação benefício/custo de 0,76 e 0,74 , respectivamente, demonstrando serem as atividades economicamente inviáveis.

A presente avaliação econômica não considerou, pela metodologia empregada, outras conseqüências 
TABELA 6. Custo do investimento total e custo médio de produção por arroba de carcaça.

\begin{tabular}{ccc}
\hline Módulos & $\begin{array}{c}\text { Custo do } \\
\text { investimento total } \\
\text { (US\$/arroba } \\
\text { de carcaça) }\end{array}$ & $\begin{array}{c}\text { Custo médio } \\
\text { de produção } \\
\text { (US\$/arroba } \\
\text { de carcaça) }\end{array}$ \\
\hline T1 & 20,92 & 17,24 \\
T2 & 12,61 & 16,65 \\
T3 & 9,11 & 14,51 \\
T4 & 14,37 & 16,81 \\
T5 & 11,57 & 23,56 \\
T6 & 11,93 & 24,31 \\
\hline
\end{tabular}

da prática da pecuária em pastagem em estado de degradação. Na realidade, o manejo das pastagens é mais dependente do rebanho e da disponibilidade de pasto num determinado período e da infra-estrutura dos piquetes. Assim sendo, o que se tem verificado na pecuária nacional, em especial nos trópicos, é a falta de pasto na entressafra, aumentando o tempo para o abate e condicionando o rebanho a mais e maiores riscos. Estes, por sua vez, fazem com que seja depreciado o valor final do produto, ao mesmo tempo em que onera os custos de manutenção, com reflexos no aumento da degradação dos pastos.

TABELA 7. Estimativa do fluxo de caixa no período de cinco anos (US\$).

\begin{tabular}{|c|c|c|c|c|c|}
\hline Itens & Ano 1 & Ano 2 & Ano 3 & Ano 4 & Ano 5 \\
\hline \multicolumn{6}{|c|}{ Módulo T1 } \\
\hline Receita & $18.045,81$ & $36.091,62$ & $36.091,62$ & $36.091,62$ & $36.091,62$ \\
\hline Arroba/ano & $1.002,55$ & $2.005,09$ & $2.005,09$ & $2.005,09$ & $2.005,09$ \\
\hline Preço arroba (US\$) & 18,00 & 18,00 & 18,00 & 18,00 & 18,00 \\
\hline Despesas & $21.357,82$ & $34.577,61$ & $34.577,61$ & $32.887,85$ & $32.887,85$ \\
\hline Custo operacional & $12.409,93$ & $24.819,85$ & $24.819,85$ & $24.819,85$ & $24.819,85$ \\
\hline Depreciação & $6.816,87$ & $7.241,54$ & $7.241,54$ & $5.809,54$ & $5.809,54$ \\
\hline Pastagem cultivada & $4.960,20$ & $4.960,20$ & $4.960,20$ & $4.960,20$ & $4.960,20$ \\
\hline Calagem & $1.432,00$ & $1.432,00$ & $1.432,00$ & 0,00 & 0,00 \\
\hline Cerca & 421,34 & 842,67 & 842,67 & 842,67 & 842,67 \\
\hline Bebedouro & 3,34 & 6,67 & 6,67 & 6,67 & 6,67 \\
\hline Juros & $2.131,02$ & $2.516,22$ & $2.516,22$ & $2.258,46$ & $2.258,46$ \\
\hline Juros past. cultivada & $1.488,06$ & $1.488,06$ & $1.488,06$ & $1.488,06$ & $1.488,06$ \\
\hline Juros calagem & 257,76 & 257,76 & 257,76 & 0,00 & 0,00 \\
\hline Juros cerca & 379,20 & 758,40 & 758,40 & 758,40 & 758,40 \\
\hline Juros bebedouro & 6,00 & 12,00 & 12,00 & 12,00 & 12,00 \\
\hline Lucro líquido & $-3.312,01$ & $1.514,01$ & $1.514,01$ & $3.203,77$ & $3.203,77$ \\
\hline Rel. benefício/custo & 0,84 & 1,04 & 1,04 & 1,10 & 1,10 \\
\hline \multicolumn{6}{|c|}{ Módulo T2 } \\
\hline Receita & $13.117,35$ & $31.481,64$ & $31.481,64$ & $31.481,64$ & $31.481,64$ \\
\hline Arroba/ano & 728,74 & $1.748,98$ & $1.748,98$ & $1.748,98$ & $1.748,98$ \\
\hline Preço arroba (US\$) & 18,00 & 18,00 & 18,00 & 18,00 & 18,00 \\
\hline Despesas & $13.758,64$ & $29.117,53$ & $29.117,53$ & $27.964,67$ & $27.964,67$ \\
\hline Custo operacional & $10.295,75$ & $24.709,79$ & $24.709,79$ & $24.709,79$ & $24.709,79$ \\
\hline Depreciação & $2.588,69$ & $3.084,14$ & $3.084,14$ & $2.107,14$ & $2.107,14$ \\
\hline Pastagem cultivada & $1.257,80$ & $1.257,80$ & $1.257,80$ & $1.257,80$ & $1.257,80$ \\
\hline Calagem & 977,00 & 977,00 & 977,00 & 0,00 & 0,00 \\
\hline Cerca & 351,11 & 842,67 & 842,67 & 842,67 & 842,67 \\
\hline Bebedouro & 2,78 & 6,67 & 6,67 & 6,67 & 6,67 \\
\hline Juros & 874,20 & $1.323,60$ & $1.323,60$ & $1.147,74$ & $1.147,74$ \\
\hline Juros past. cultivada & 377,34 & 377,34 & 377,34 & 377,34 & 377,34 \\
\hline Juros calagem & 175,86 & 175,86 & 175,86 & 0,00 & 0,00 \\
\hline Juros cerca & 316,00 & 758,40 & 758,40 & 758,40 & 758,40 \\
\hline
\end{tabular}


TABELA 7. Continuação.

\begin{tabular}{|c|c|c|c|c|c|}
\hline Itens & Ano 1 & Ano 2 & Ano 3 & Ano 4 & Ano 5 \\
\hline Juros bebedouro & 5,00 & 12,00 & 12,00 & 12,00 & 12,00 \\
\hline Lucro líquido & $-641,29$ & $2.364,11$ & $2.364,11$ & $3.516,97$ & $3.516,97$ \\
\hline Rel. benefício/custo & 0,95 & 1,08 & 1,08 & 1,13 & 1,13 \\
\hline \multicolumn{6}{|c|}{ Módulo T3 } \\
\hline Receita & $14.482,43$ & $34.757,82$ & $34.757,82$ & $34.757,82$ & $34.757,82$ \\
\hline Arroba/ano & 804,58 & $1.930,99$ & $1.930,99$ & $1.930,99$ & $1.930,99$ \\
\hline Preço arroba (US\$) & 18,00 & 18,00 & 18,00 & 18,00 & 18,00 \\
\hline Despesas & $12.623,18$ & $28.022,05$ & $28.022,05$ & $26.869,19$ & $26.869,19$ \\
\hline Custo operacional & $10.324,30$ & $24.778,33$ & $24.778,33$ & $24.778,33$ & $24.778,33$ \\
\hline Depreciação & $1.693,29$ & $2.188,74$ & $2.188,74$ & $1.211,74$ & $1.211,74$ \\
\hline Pastagem cultivada & 362,40 & 362,40 & 362,40 & 362,40 & 362,40 \\
\hline Calagem & 977,00 & 977,00 & 977,00 & 0,00 & 0,00 \\
\hline Cerca & 351,11 & 842,67 & 842,67 & 842,67 & 842,67 \\
\hline Bebedouro & 2,78 & 6,67 & 6,67 & 6,67 & 6,67 \\
\hline Juros & 605,58 & $1.054,98$ & $1.054,98$ & 879,12 & 879,12 \\
\hline Juros past. cultivada & 108,72 & 108,72 & 108,72 & 108,72 & 108,72 \\
\hline Juros calagem & 175,86 & 175,86 & 175,86 & 0,00 & 0,00 \\
\hline Juros cerca & 316,00 & 758,40 & 758,40 & 758,40 & 758,40 \\
\hline Juros bebedouro & 5,00 & 12,00 & 12,00 & 12,00 & 12,00 \\
\hline Lucro líquido & $1.859,25$ & $6.735,77$ & $6.735,77$ & $7.888,63$ & $7.888,63$ \\
\hline Rel. benefício/custo & 1,15 & 1,24 & 1,24 & 1,29 & 1,29 \\
\hline \multicolumn{6}{|c|}{ Módulo T4 } \\
\hline Receita & $15.970,95$ & $31.941,90$ & $31.941,90$ & $31.941,90$ & $31.941,90$ \\
\hline Arroba/ano & 887,28 & $1.774,55$ & $1.774,55$ & $1.774,55$ & $1.774,55$ \\
\hline Preço arroba (US\$) & 18,00 & 18,00 & 18,00 & 18,00 & 18,00 \\
\hline Despesas & $16.672,97$ & $29.836,86$ & $29.836,86$ & $29.194,55$ & $29.194,55$ \\
\hline Custo operacional & $12.354,03$ & $24.708,05$ & $24.708,05$ & $24.708,05$ & $24.708,05$ \\
\hline Depreciação & $3.174,20$ & $3.598,87$ & $3.598,87$ & $3.054,54$ & $3.054,54$ \\
\hline Pastagem cultivada & $2.205,20$ & $2.205,20$ & $2.205,20$ & $2.205,20$ & $2.205,20$ \\
\hline Calagem & 544,33 & 544,33 & 544,33 & 0,00 & 0,00 \\
\hline Cerca & 421,34 & 842,67 & 842,67 & 842,67 & 842,67 \\
\hline Bebedouro & 3,34 & 6,67 & 6,67 & 6,67 & 6,67 \\
\hline Juros & $1.144,74$ & $1.529,94$ & $1.529,94$ & $1.431,96$ & $1.431,96$ \\
\hline Juros past. cultivada & 661,56 & 661,56 & 661,56 & 661,56 & 661,56 \\
\hline Juros calagem & 97,98 & 97,98 & 97,98 & 0,00 & 0,00 \\
\hline Juros cerca & 379,20 & 758,40 & 758,40 & 758,40 & 758,40 \\
\hline Juros bebedouro & 6,00 & 12,00 & 12,00 & 12,00 & 12,00 \\
\hline Lucro líquido & $-702,02$ & $2.105,04$ & $2.105,04$ & $2.747,35$ & $2.747,35$ \\
\hline Rel. benefício/custo & 0,96 & 1,07 & 1,07 & 1,09 & 1,09 \\
\hline \multicolumn{6}{|c|}{ Módulo T5 } \\
\hline Receita & $19.973,88$ & $19.973,88$ & $19.973,88$ & $19.973,88$ & $19.973,88$ \\
\hline Arroba/ano & $1.109,66$ & $1.109,66$ & $1.109,66$ & $1.109,66$ & $1.109,66$ \\
\hline Preço arroba (US\$) & 18,00 & 18,00 & 18,00 & 18,00 & 18,00 \\
\hline Despesas & $26.138,80$ & $26.138,80$ & $26.138,80$ & $26.138,80$ & $26.138,80$ \\
\hline Custo operacional & $24.519,06$ & $24.519,06$ & $24.519,06$ & $24.519,06$ & $24.519,06$ \\
\hline Depreciação & 849,34 & 849,34 & 849,34 & 849,34 & 849,34 \\
\hline Cerca & 842,67 & 842,67 & 842,67 & 842,67 & 842,67 \\
\hline Bebedouro & 6,67 & 6,67 & 6,67 & 6,67 & 6,67 \\
\hline
\end{tabular}


TABELA 7. Continuação.

\begin{tabular}{|c|c|c|c|c|c|}
\hline Itens & Ano 1 & Ano 2 & Ano 3 & Ano 4 & Ano 5 \\
\hline Juros & 770,40 & 770,40 & 770,40 & 770,40 & 770,40 \\
\hline Juros cerca & 758,40 & 758,40 & 758,40 & 758,40 & 758,40 \\
\hline Juros bebedouro & 12,00 & 12,00 & 12,00 & 12,00 & 12,00 \\
\hline Lucro líquido & $-6.164,92$ & $-6.164,92$ & $-6.164,92$ & $-6.164,92$ & $-6.164,92$ \\
\hline Rel. benefício/custo & 0,76 & 0,76 & 0,76 & 0,76 & 0,76 \\
\hline \multicolumn{6}{|c|}{ Módulo T6 } \\
\hline Receita & $19.375,20$ & $19.375,20$ & $19.375,20$ & $19.375,20$ & $19.375,20$ \\
\hline Arrobas/ano & $1.076,40$ & $1.076,40$ & $1.076,40$ & $1.076,40$ & $1.076,40$ \\
\hline Preço arroba (US\$) & 18,00 & 18,00 & 18,00 & 18,00 & 18,00 \\
\hline Despesas & $26.166,04$ & $26.166,04$ & $26.166,04$ & $26.166,04$ & $26.166,04$ \\
\hline Custo operacional & $24.546,30$ & $24.546,30$ & $24.546,30$ & $24.546,30$ & $24.546,30$ \\
\hline Depreciação & 849,34 & 849,34 & 849,34 & 849,34 & 849,34 \\
\hline Cerca & 842,67 & 842,67 & 842,67 & 842,67 & 842,67 \\
\hline Bebedouro & 6,67 & 6,67 & 6,67 & 6,67 & 6,67 \\
\hline Juros & 770,40 & 770,40 & 770,40 & 770,40 & 770,40 \\
\hline Juros cerca & 758,40 & 758,40 & 758,40 & 758,40 & 758,40 \\
\hline Juros bebedouro & 12,00 & 12,00 & 12,00 & 12,00 & 12,00 \\
\hline Lucro líquido & $-6.790,84$ & $-6.790,84$ & $-6.790,84$ & $-6.790,84$ & $-6.790,84$ \\
\hline Rel. benefício/custo & 0,74 & 0,74 & 0,74 & 0,74 & 0,74 \\
\hline
\end{tabular}

\section{CONCLUSÕES}

1. Os resultados analisados, nos módulos T1, T2, T3 e T4 demonstram que a exploração da pecuária bovina de corte, a pasto recuperado, é uma atividade economicamente lucrativa.

2. A reforma de pastagem cultivada nos moldes da agricultura (módulos T1, T2 e T3) apresentam uma vantagem comparativa em relação ao módulo $\mathrm{T} 4$, devido à receita gerada pelo grão, que cobre parte dos custos da formação da pastagem.

3. A não-recuperação do pasto (módulos T5 e T6) apresenta-se como atividade economicamente inviável, pois a lotação animal é inferior com conseqüente ganho de peso menor.

4. É economicamente inviável a exploração da atividade em pastagens degradadas.

5. A maior lotação animal é no módulo T1, vindo, a seguir, em ordem decrescente, T3, T2, T4, T6 e T5.

6. A recuperação de pastagem em consórcio com o milho é a melhor alternativa, desde que se obtenha a produtividade do milho em torno de $3.600 \mathrm{~kg} / \mathrm{ha}$.
7. O custo médio de produção de uma arroba de carcaça nos módulos T1, T2, T3 e T4 permite uma margem de renda líquida.

8. Há evidências de que a implementação e manutenção da pastagem cultivada nos moldes de agricultura, em associação com arroz ou milho, é uma atividade economicamente viável.

9. Os resultados econômicos desses sistemas demonstram ser a pecuária bovina de corte, sob pastejo rotacionado, uma atividade economicamente compensadora e que responde positivamente aos investimentos em tecnologia, quando sustentados por uma boa administração.

\section{REFERÊNCIAS}

ARRUDA, Z.J. de; CORREA, E.S. Avaliação técnicoeconômica de sistemas de produção de gado de corte: o sistema físico de produção do CNPGC. Campo Grande: Embrapa-CNPGC, 1992. 10p. (Embrapa-CNPGC. Comunicado técnico, 42).

ARRUDA, Z.J. de; CORREA, E.S.; ZIMMER, A.H. Avaliação técnico-econômica de alternativa para o sistema físico de produção de gado de corte do 
CNPGC: $80 \%$ de pasto cultivado. Campo Grande: Embrapa-CNPGC, 1992. 8p. (Embrapa-CNPGC. Comunicado técnico, 43).

HOFFMANN, R.; ENGLER, J.J. de C.; SERRANO, O.; THAME, A.C. de M.; NEVES, E.M. Administração da empresa agrícola. 3.ed. São Paulo: Pioneira, 1981.247p.

KLUTHCOUSKI, J.; PACHECO, A.R.; TEIXEIRA, S.M.; OLIVEIRA, E.T. de. Renovação de pastagens de cerrado com arroz. I. Sistema Barreirão. Goiânia: Embrapa-CNPAF, 1991. 20p. (EmbrapaCNPAF. Documentos, 33).

OLIVEIRA, I.P. de; KLUTHCOUSKI, J.; YOKOYAMA, L.P.; DUTRA, L.G.; PORTES, T. de A.; SILVA, E.A. da; PINHEIRO, B. da S.; FERREIRA, E.; CASTRO, E. da M. de; GUIMARÃES, C.M.; GOMIDE, J. de C.; BALBINO, L.C. Sistema Barreirão: recuperação/renovação de pastagens degradadas em consórcio com culturas anuais. Goiânia: Embrapa-CNPAF-APA, 1996. 90p. (Embrapa-CNPAF. Documentos, 64).
SEGUY, L.; BOUZINAC, S.R.R.; DOUZET, J.M. Gestão dos solos e das culturas nas áreas de fronteiras agrícolas dos Cerrados úmidos e das florestas no Centro-Oeste brasileiro - Região CentroNorte do Mato Grosso: Campanha agrícola 1993/94. Lucas do Rio Verde: RPA/COOPERLUCAS/CIRAD-CA, 1994. 259p.

YOKOYAMA, L.P.; KLUTHCOUSKI, J.; OLIVEIRA, I.P. de; DUTRA, L.G.; SILVA, J.G. da; GOMIDE, J. de C.; BUSO, L.H. Sistema Barreirão: análise de custo/benefício e necessidade de máquinas e implementos agrícolas. Goiânia: Embrapa-CNPAFAPA, 1995. 31p. (Embrapa-CNPAF. Documentos, 56).

ZIMMER, A.H.; MACEDO, M.C.M.; BARCELLOS, A. de O.; KICHEL, A.N. Estabelecimento e recuperação de pastagens de braquiária. In: SIMPÓSIO SOBRE MANEJO DE PASTAGEM, 11., 1994, Piracicaba. Anais... Piracicaba: FEALQ, 1994. p.153-208 